\title{
Efeito da utilização de farelo de girassol na dieta sobre o desempenho de frangos de corte ${ }^{1}$
}

\author{
Fernando de Castro Tavernari ${ }^{1}$, Wilson Moreira Dutra Junior ${ }^{2}$, Luiz Fernando Teixeira \\ Albino $^{3}$, Horacio Santiago Rostagno ${ }^{3}$, Rodolfo Alves Vieira ${ }^{4}$, Carla Rodrigues da Silva ${ }^{1}$
}

\footnotetext{
${ }^{1}$ Pós-graduação em Zootecnia - UFV.

2 Departamento de Zootecnia - UFRPE.

${ }^{3}$ Departamento de Zootecnia - UFV.

${ }^{4}$ Graduação em Zootecnia - UFV.
}

RESUMO - Foi realizado um experimento para avaliar os efeitos da inclusão de farelo de girassol em rações para frangos de corte sobre o desempenho, o rendimento de carcaça e dos cortes e a viabilidade econômica. O delineamento experimental foi em blocos casualizados com cinco níveis de farelo de girassol $(0,5,10,15$ e $20 \%$ da dieta basal), oito repetições e 20 aves por unidade experimental. As aves e as rações foram pesadas no início e ao final de cada fase do período experimental (1 a 21 dias e 22 a 42 dias) para obtenção do consumo de ração, do ganho de peso e da conversão alimentar. Duas aves de cada repetição foram abatidas aos 42 dias de idade para avaliação da carcaça. Com a inclusão do farelo de girassol, o consumo diminuiu linearmente na fase inicial $\left(y=1185,1-2,1 x ; R^{2}=0,97\right)$, enquanto a conversão alimentar melhorou de forma linear no período total $\left(y=1,6404-0,0018 x ; R^{2}=0,62\right)$ e de forma quadrática na fase inicial $\left(y=1,3943-0,0069 x+0,0002 x^{2}\right.$; $\left.\mathrm{R}^{2}=0,96\right)$. Não foi encontrada diferença significativa no rendimento de carcaça e dos cortes. Os melhores desempenhos econômicos foram obtidos quando as aves foram alimentadas com rações contendo $5 \%$ de farelo de girassol na fase inicial e $0 \%$ na fase de crescimento e no período total. A adição de $20 \%$ de farelo de girassol em rações para frangos de corte até os 42 dias de idade não prejudica o desempenho produtivo das aves.

Palavras-chave: alimento alternativo, avicultura, carcaça

\section{Effect of different levels of sunflower meal in diets on the performance of broiler chickens}

\begin{abstract}
A trial was carried out to evaluate the effect of sunflower meal inclusion in the broiler diets on the performance, carcass yield and cuts and the economics viability. A randomized block experimental design was used, with five treatments and eight replications of 20 birds per experimental unit. Treatments consisted of including $0,5,10$, 15, or $20 \%$ sunflower meal in a basal diet. Birds and diets were weighed at the beginning and at the end of each experimental phase (1 to 21 days and 22 to 42 days) to determine feed intake, weight gain, and the feed:gain ratio. Two birds per replication were slaughtered at 42 days of age for carcass evaluation. Feed intake was linearly reduced in the starter phase $(y=1185.1-2.1 \mathrm{x}$; $\left.\mathrm{R}^{2}=0.97\right)$, with sunflower meal inclusion in the basal diet, and the feed:gain ratio linearly improved in the total period $\left(y=1.6404-0.0018 x ; R^{2}=0.62\right)$, whereas a quadratic effect on the feed:gain ratio was observed in the starter phase $\left(y=1.3943-0.0069 x+0.0002 x^{2} ; R^{2}=0.96\right)$. No significant differences were observed for carcass yield and cuts. The best economic performances were achieved when the birds were fed diets containing $5 \%$ sunflower meal in the starter phase, and $0 \%$ in the grower phase and total period. The inclusion of $20 \%$ sunflower meal in the diet of broilers up to 42 days of age did not show harmful effects on performance.
\end{abstract}

Key Words: alternative feedstuffs, carcass, poultry production

\section{Introdução}

Nutricionistas têm buscado alternativas que tornem as formulações de rações mais eficientes, reduzindo custos e diminuindo a poluição ambiental. O uso de alimentos que substituam o milho e/ou a soja nas rações é uma boa alternativa. O farelo de girassol é um subproduto que pode ser utilizado como alternativa na substituição ao farelo de soja em rações para frangos de corte, entretanto, apresenta baixo nível de lisina, elevado teor de fibra e baixo valor de energia metabolizável (Senkoylu \& Dale, 1999), fatores que podem limitar sua inclusão em rações para aves. 
Segundo Waldroup et al. (1970), 20\% é o nível máximo de farelo de girassol que pode ser utilizado em rações para frangos de corte, sem a adição de lisina sintética, concordando com indicações de Costa (1974), Valdivie et al. (1982) e Zatari \& Sell (1990). Por outro lado, Ibrahim \& ElZubeir(1991) verificaram que o farelo de girassol pode ser utilizado nas rações até o nível de $30 \%$.

Rad \& Keshavarz (1976) relataram que 17,5\% de farelo de soja pode ser incluído nas rações sem suplementação de lisina, pois não tem sem efeito adverso no crescimento e na conversão alimentar de frangos de corte até 30 dias de idade.

Furlan et al. (2001) concluíram como melhor nível 15\% de inclusão do farelo de girassol nas rações para frangos de corte com suplementação de lisina, o que representa $30 \%$ a menos de farelo de soja na ração. Entretanto, Oliveira et al. (2003) concluíram que é possível a inclusão de 15\% de farelo de girassol sem correção do teor de lisina e que sua utilização não afeta o desempenho geral e o rendimento de carcaça de frangos de corte aos 42 dias de idade.

A idade dos animais também é extremamente importante para determinar o nível de substituição. Pinheiro et al. (2002) observaram melhor desempenho econômico quando os frangos foram alimentados com rações sem farelo de girassol dos 3 até 35 dias e com 4\% de farelo de girassol dos 36 aos 42 dias de idade.

Objetivou-se avaliar os efeitos da utilização de farelo de girassol na ração de frangos de corte sobre o desempenho das aves, o rendimento de carcaça e dos cortes e a viabilidade econômica da produção.

\section{Material e Métodos}

O experimento foi realizado no Setor de Avicultura do Departamento de Zootecnia da Universidade Federal de Viçosa. As temperaturas médias registradas durante o experimento foram: de 1 a 21 dias $25,5^{\circ} \mathrm{C}\left(20,0\right.$ e $31,0^{\circ} \mathrm{C}$ de mínima e máxima, respectivamente); de 21 a 42 dias $24,5^{\circ} \mathrm{C}$ (19,0 e 30,0 C de mínima e máxima, respectivamente).

Foram utilizados 800 pintos de corte machos, da linhagem Cobb, de 1 a 42 dias idade, alojados em galpão de alvenaria, telado e coberto com telhas de barro, subdividido em boxes de 1,0 × 1,5 m com cama de maravalha e providos de um bebedouro tipo nipple e um comedouro tubular. $\mathrm{O}$ manejo foi realizado de acordo com o manual da linhagem (Cobb Vantress, 2003).

O delineamento experimental foi em blocos casualizados com 5 níveis de farelo de girassol ( 0, 5, 10, 15 ou 20\%),
8 repetições e 20 aves por unidade experimental. As rações foram isocalóricas e isoproteicas, continham as mesmas quantidades dos principais aminoácidos digestíveis e foram formuladas para atender às exigências nutricionais das aves, segundo Rostagno et al. (2005) (Tabelas 1 e 2). O farelo de girassol utilizado continha 89,95\% de MS, 28,09\% de $\mathrm{PB}$ e $22,37 \%$ de FB.

A mortalidade foi registrada para ser considerada durante a correção dos dados de desempenho. As aves e as rações foram pesadas no início e ao final de cada fase do período experimental ( 1 a 21 dias e 22 a 42 dias) para obtenção do ganho de peso, do consumo de ração e da conversão alimentar aos 21 e aos 42 dias de idade, da viabilidade e do índice de eficiência produtiva (IEP) aos 42 dias de idade, segundo a fórmula: Viabilidade $=100$ - $\mathrm{MO}$ e IEP $=((\mathrm{PM} *$ Viabilidade $) / \mathrm{IA} * \mathrm{CA}) * 100$, em que $\mathrm{MO}=$ mortalidade; $\mathrm{PM}=$ peso médio do lote ao abate; $\mathrm{ID}=$ idade de abate; e CA = conversão alimentar.

Duas aves de cada repetição foram abatidas aos 42 dias de idade para avaliação dos rendimentos de carcaça, de peito, de filé de peito, de coxa e sobrecoxa e de gordura abdominal, em relação ao peso da carcaça fria (após a saída do chiller).

Para verificar a viabilidade econômica da inclusão do farelo de girassol nas rações, determinou-se o custo da ração, em reais ( $\mathrm{R}$ ), por quilograma de peso vivo ganho (Yi), segundo Bellaver et al. (1985): $\mathrm{Yi}=(\mathrm{Pi} * \mathrm{Qi}) / \mathrm{Gi}$, em que $\mathrm{Yi}$ = custo da ração por quilograma de peso vivo ganho no i-ésimo tratamento (nível de farelo de girassol); $\mathrm{Pi}$ = preço por quilograma da ração utilizada no i-ésimo tratamento; Qi, quantidade de ração consumida no i-ésimo tratamento; e Gi = ganho de peso do i-ésimo tratamento. Em seguida, foi calculado o índice de eficiência econômica (IEE): IEE = (MCe / CTei) * 100, em que MC = menor custo da ração por quilograma ganho observado entre os tratamentos; e CTei = custo do tratamento i considerado.

A análise da regressão foi empregada para avaliar o consumo de ração, o ganho de peso, a conversão alimentar e as características de carcaça analisadas, adotando-se o nível de significância de 5\%, utilizando as funções linear e quadrática do software estatístico SAEG - Sistema de Análises Estatísticas e Genéticas (UFV, 2000).

\section{Resultados e Discussão}

$\mathrm{Na}$ fase inicial, observou-se efeito linear $(\mathrm{P}<0,05)$ dos níveis de farelo de girassol sobre o consumo de ração (Tabela 3) e esse efeito foi comprovado pela equação 
Tabela 1 - Composição das rações fornecidas na fase inicial, de 1 a 21 dias de idade

\begin{tabular}{|c|c|c|c|c|c|}
\hline \multirow[t]{2}{*}{ Ingrediente (\%) } & \multicolumn{5}{|c|}{ Nível de farelo de girassol (\%) } \\
\hline & 0 & 5 & 10 & 15 & 20 \\
\hline Milho & 56,96 & 53,70 & 50,42 & 47,17 & 43,89 \\
\hline Farelo de girassol & 0,00 & 5,00 & 10,00 & 15,00 & 20,00 \\
\hline Óleo de soja & 2,30 & 3,05 & 3,80 & 4,55 & 5,30 \\
\hline Fosfato bicálcico & 1,85 & 1,81 & 1,78 & 1,74 & 1,71 \\
\hline DL-metionina 99\% & 0,24 & 0,23 & 0,22 & 0,22 & 0,21 \\
\hline L-lisina $\mathrm{HCl}$ 99\% & 0,15 & 0,19 & 0,24 & 0,28 & 0,33 \\
\hline L-treonina $98 \%$ & 0,03 & 0,04 & 0,05 & 0,05 & 0,06 \\
\hline Premix vitamínico ${ }^{1}$ & 0,10 & 0,10 & 0,10 & 0,10 & 0,10 \\
\hline Premix mineral ${ }^{2}$ & 0,05 & 0,05 & 0,05 & 0,05 & 0,05 \\
\hline Cloreto de colina $60 \%$ & 0,10 & 0,10 & 0,10 & 0,10 & 0,10 \\
\hline Energia metabolizável, kcal/kg & 2.975 & 2.975 & 2.975 & 2.975 & 2.975 \\
\hline Proteína bruta, \% & 21,50 & 21,50 & 21,50 & 21,50 & 21,50 \\
\hline Proteína bruta, $\%^{4}$ & 21,19 & 21,43 & 21,70 & 21,82 & 21,31 \\
\hline Fibra bruta, \% & 2,97 & 3,90 & 4,83 & 5,75 & 6,68 \\
\hline Cálcio, \% & 0,91 & 0,91 & 0,91 & 0,91 & 0,91 \\
\hline Fósforo total, \% & 0,67 & 0,69 & 0,70 & 0,72 & 0,73 \\
\hline Fósforo disponível, \% & 0,45 & 0,45 & 0,45 & 0,45 & 0,45 \\
\hline Lisina digestível, \% & 1,17 & 1,17 & 1,17 & 1,17 & 1,17 \\
\hline Metionina + Cistina digestível, \% & 0,83 & 0,83 & 0,83 & 0,83 & 0,83 \\
\hline Metionina digestível, \% & 0,54 & 0,54 & 0,54 & 0,54 & 0,54 \\
\hline
\end{tabular}

$y=1185,1-2,1 x\left(R^{2}=0,97\right)$. A redução no consumo de ração com o aumento do nível de farelo de girassol pode ser atribuída ao teor de fibra das rações, contudo, Furlan et al. (2001), testando os níveis de 0, 5, 10, 15, 20 e 25\% de farelo de girassol na fase inicial, não encontraram efeito sobre o consumo de ração nesta fase.

Sabe-se que aves jovens alimentadas com ração contendo alta quantidade de fibra solúvel apresentam redução no consumo, em decorrência do maior tempo de passagem do alimento pelo trato digestório (Choct, 2002), o que pode acarretar aumento na população de microrganismos que competem com o hospedeiro pelos nutrientes presentes no lúmen e também produzir toxinas, prejudicando o desempenho dos animais (Nunes et al., 2001). Contudo, não foi observado efeito significativo dos níveis de farelo de girassol sobre o ganho de peso dos animais.

Os níveis de farelo de girassol na dieta tiveram efeito quadrático $(\mathrm{P}<0,05)$ sobre a conversão alimentar na fase inicial e esse efeito pode ser representado pela equação $y=1,3943-0,0069 x+0,0002 x^{2}\left(R^{2}=0,96\right)$, com nível ótimo de $17,25 \%$ de farelo de girassol na ração, superior ao de 14,23\% encontrado por Furlan et al. (2001). Pinheiro et al. (2002) não encontraram diferenças significativas no consumo de ração, no ganho de peso e na conversão alimentar de frangos de corte no período de 3 a 21 dias de vida alimentados com dietas contendo até $12 \%$ de farelo de girassol.

Não foram encontrados valores significativos para os parâmetros avaliados na fase de crescimento, embora no nível de $10 \%$ de farelo de girassol tenham sido observados o menor consumo, o maior ganho de peso e a melhor conversão alimentar. Furlan et al. (2001) encontraram como pontos de máxima para consumo de ração e ganho de peso 13,17 e 12,04\% de farelo de girassol na fase de crescimento, respectivamente.

No período total, não houve efeito significativo da inclusão de farelo de girassol na dieta sobre o consumo de ração e o ganho de peso, porém observou-se efeito linear $(\mathrm{P}<0,05)$ dos níveis de farelo de girassol sobre a conversão alimentar, comprovado pela equação y = 1,6404 - 0,0018x 
Tabela 2 - Composição das rações fornecidas na fase de crescimento, de 22 a 42 dias de idade

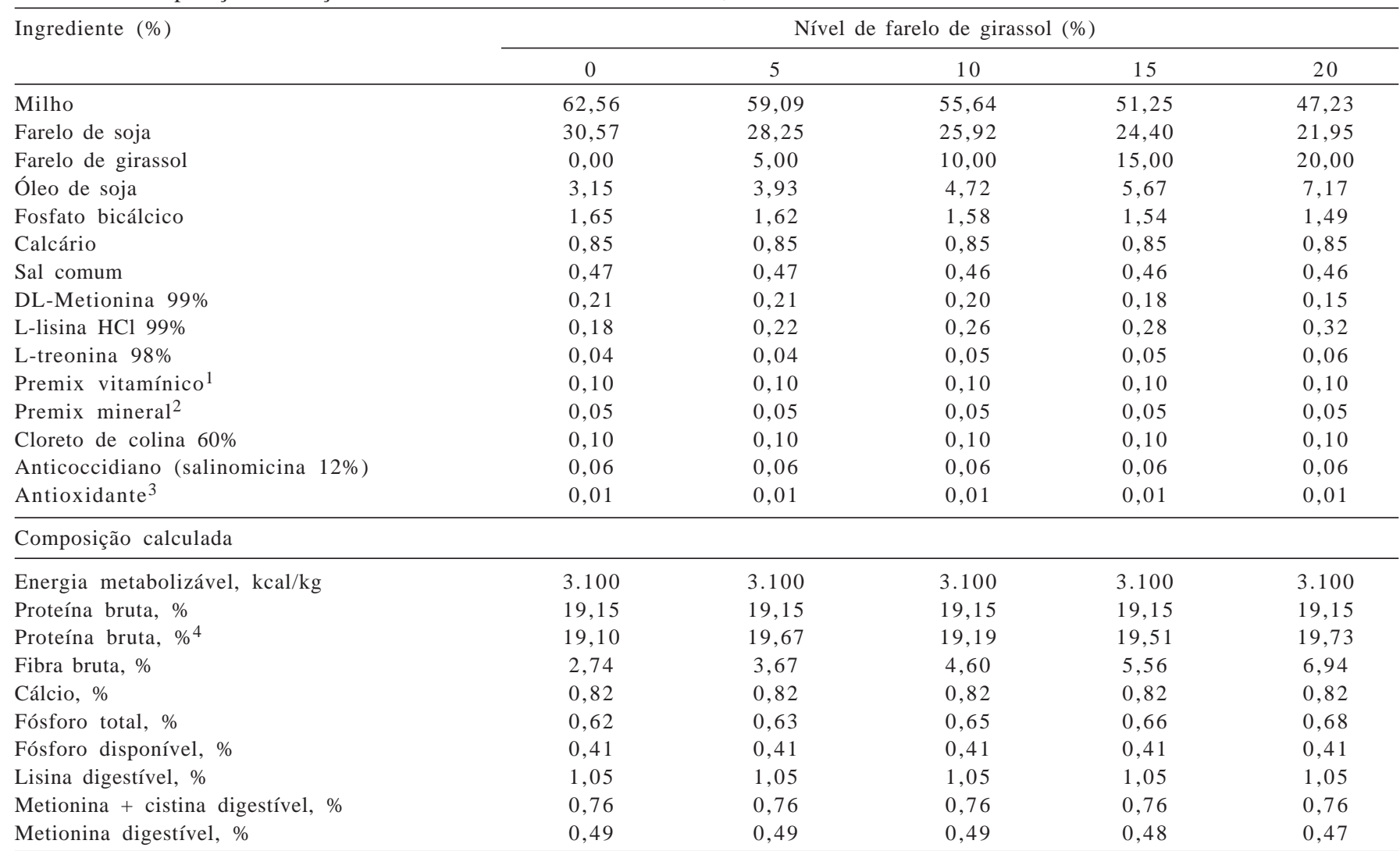

${ }^{1}$ Mistura vitamínica (kg do produto): vit. A - 10.000.000 U.I.; vit. D3 - 2.000.000 U.I.; vit. E - 30.000 U.I.; vit. B1 - 2,0 g; vit. B2 - 6,0 g; vit. B6 - 4,0 g; vit. B12 - 0,015 g; ácido pantotênico - 12,0 g; biotina - 0,1 g; vit. K3 - 3,0 g; ácido fólico - 1,0 g; ácido nicotínico - 50,0 g; Se - 250,0 mg.

${ }^{2}$ Mistura mineral (kg do produto): Fe - 80 g; Cu - 10 g; Co - 2 g; Mn - 80 g; Zn - 50 g; I - 1 g.

3 Antioxidante: BHT (Butil hidroxi tolueno).

${ }^{4}$ Valor determinado (Laboratório de Nutrição Animal do Departamento de Zootecnia da UFV).

Tabela 3 - Consumo de ração, ganho de peso e conversão alimentar nas fases inicial e de crescimento e no período total, viabilidade econômica (\%) e índice de eficiência produtiva (IEP) no período total

\begin{tabular}{|c|c|c|c|c|c|c|}
\hline & \multicolumn{5}{|c|}{ Nível de farelo de girassol (\%) } & $\mathrm{CV}(\%)^{1}$ \\
\hline \multicolumn{7}{|l|}{ Fase inicial (1 a 21 dias) } \\
\hline Ganho de peso (g/ave) & 852 & 858 & 861 & 871 & 850 & 3,307 \\
\hline Conversão alimentar $(\mathrm{g} / \mathrm{g})^{3}$ & 1,392 & 1,369 & 1,349 & 1,331 & 1,344 & 1,999 \\
\hline Ganho de peso (g/ave) & 1.799 & 1.818 & 1.831 & 1.830 & 1.825 & 3,277 \\
\hline Conversão alimentar (g/g) & 1,775 & 1,750 & 1,727 & 1,746 & 1,740 & 2,673 \\
\hline \multicolumn{7}{|l|}{ Período total (1 a 42 dias) } \\
\hline Consumo de ração (g/ave) & 4.377 & 4.356 & 4.322 & 4.352 & 4.315 & 2,886 \\
\hline Ganho de peso (g/ave) & 2.651 & 2.676 & 2.692 & 2.700 & 2.675 & 2,805 \\
\hline
\end{tabular}

\footnotetext{
${ }_{1}^{1}$ Coeficiente de variação (\%)

2 Efeito linear $(\mathrm{P}<0,05)$.

${ }^{3}$ Efeito quadrático $(\mathrm{P}<0,05)$.
} 
$\left(\mathrm{R}^{2}=0,62\right)$, tornando-se possível a inclusão de $20 \%$ de farelo de girassol nas rações para frangos de corte sem prejudicar o desempenho das aves. Esse resultado é superior ao apresentado por Rad \& Keshavarz (1976) e Furlan et al. (2001) e inferior ao apresentado por Ibrahim \& El zubeir (1991).

Os níveis de farelo de girassol não influenciaram ( $\mathrm{P}>0,05)$ as características de carcaça avaliadas (Tabela 4), o que indica que, no período total de criação, a inclusão de $20 \%$ de farelo de girassol na dieta de frangos de corte não prejudica o rendimento de carcaça. Oliveira et al. (2003), avaliando os níveis de 0, 15 e 30\% de farelo de girassol para frangos de corte, não notaram alterações significativas no rendimento de carcaça e dos cortes.

Ressalta-se que, no caso de dietas contendo elevado teor de fibra, para o melhor balanceamento energético, é necessária a inclusão de óleo vegetal nas rações. O National Research Council (NRC, 1994) destaca o efeito extracalórico como efeito benéfico do uso de óleo nas formulações, uma vez que esse efeito provoca principalmente melhora na palatabilidade e na conversão alimentar. O efeito extracalórico do óleo refere-se à sua maior energia líquida, portanto, a ave dispõe de mais energia para o desempenho produtivo (Franco, 1992), o que torna difícil avaliar os efeitos de alimentos fibrosos no desempenho de aves sem considerar os níveis de óleo utilizados nas rações.

Apesar de no período de 1 a 21 dias o custo por quilograma de peso vivo ganho ter sido o mesmo para todas as rações com $0 \%$ e $5 \%$ de farelo de girassol (Tabela 5), nesta fase o melhor índice de eficiência econômica foi obtido no nível de 5\%. Para a fase de crescimento e para o período total, o menor custo de ração por quilograma de peso vivo ganho e o melhor índice de eficiência econômica foram obtidos quando os frangos foram alimentados com ração contendo 0\% de farelo de girassol. Furlan et al. (2001) encontraram o mesmo resultado para o período de 1 a 42 dias de idade, enquanto Pinheiro et al. (2002) observaram melhor desempenho econômico quando os frangos foram alimentados com $0 \%$ de farelo de girassol dos 3 até 35 dias e $4 \%$ dos 36 aos 42 dias de idade.

Embora o farelo de girassol tenha apresentado custo menor que o do farelo de soja, no período em que foi realizado o experimento, os níveis e o preço do óleo utilizado nas rações contendo farelo de girassol tornaram esass rações mais caras que aquela sem farelo de girassol.

Tabela 4 - Rendimento de carcaça, gordura abdominal, peito, filé de peito e coxa e sobrecoxa de aves alimentadas com rações contendo farelo de girassol e abatidas aos 42 dias de idade ${ }^{1}$

\begin{tabular}{lccccc}
\hline Rendimento, \% & \multicolumn{3}{c}{ Nível de farelo de girassol } & CV $(\%)^{2}$ \\
\cline { 2 - 5 } & $0 \%$ & $5 \%$ & $10 \%$ & $15 \%$ & $20 \%$ \\
\hline Carcaça & 76,47 & 76,80 & 75,61 & 75,15 & 75,93 \\
Gordura abdominal & 1,43 & 1,46 & 1,67 & 1,41 & 2,192 \\
Peito & 34,75 & 34,62 & 33,89 & 35,53 & 1,47 \\
Filé de peito & 27,26 & 27,18 & 26,22 & 27,84 & 34,67 \\
Coxa e sobrecoxa & 27,71 & 27,19 & 27,61 & 27,67 & 26,94 \\
\hline
\end{tabular}

${ }^{1}(\mathrm{P}>0,05)$.

2 Coeficiente de variação (\%).

Tabela 5 - Custo de ração e índice de eficiência econômica de frangos alimentados com rações contendo farelo de girassol

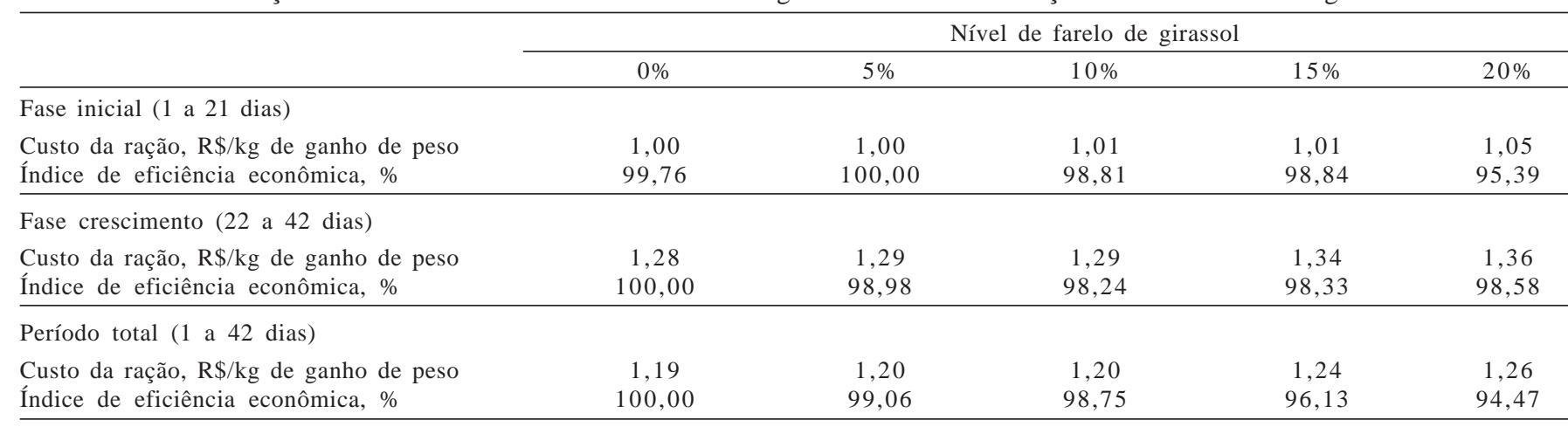




\section{Conclusões}

A utilização de farelo de girassol em níveis de até 20\% em dietas para frangos de corte não prejudica o desempenho e o rendimento de carcaça. A inclusão de farelo de girassol não é economicamente viável para as fases de crescimento e para o período total de criação, mas, dependendo do preço, o nível de $5 \%$ pode ser viável para a fase inicial.

\section{Agradecimentos}

Ao Programa de Cooperação Acadêmica (PROCAD/ CAPES), pela possibilidade de realização do mestrado sanduíche, e à Bunge Alimentos, pelo fornecimento do farelo de girassol.

\section{Literatura Citada}

BELLAVER, C.; FIALHO, E.T.; PROTAS, J.F.S. et al. Radícula de malte na alimentação de suínos em crescimento e terminação. Pesquisa Agropecuária Brasileira, v.20, n.8, p.969-974, 1985.

CHOCT, M. Non-starch polysaccharides: effect on nutritive value. In: Poultry feedstuffs: supply, composition and nutritive value In: MACNAB, J.M.; BOORMAN, K.N. (Eds.) Factors influencing nutritive value. Wallingford: $C A B$ Internacional, 2002. p.221-235.

COBB VANTRESS. Cobb $\mathbf{5 0 0}$ broiler management guide. Guapiaçu: Cobb, 2003. p.65.

COSTA, C.P. Influência da lisina nas dietas contendo farelo de girassol para frangos de corte. 1974. 35f. Dissertação (Mestrado em Zootecnia) - Universidade Federal de Minas Gerais, Belo Horizonte, 1974.

FRANCO, S.G. Programas de alimentação e fontes de óleo para frangos de corte. 1992. 118f. Tese (Doutorado em Produção Animal) - Universidade Estadual Paulista, Jaboticabal, 1998.
FURLAN, A.C.; MANTOVANi, C.; MURAKAMI, A.E. et al Utilização do farelo de girassol na alimentação de frangos de corte. Revista Brasileira de Zootecnia, v.30, n.1, p.158-164, 2001.

IBRAHIM, M.A.; EL ZUBEIR, E.A. Higher fiber sunflower meal in broiler chick diets. Animal Feed Science and Technology, v.33, n.3-4, p.343-347, 1991.

NUNES, R.V.; BUTERI, C.B.; NUNES, C.G.V. et al. Fatores antinutricionais dos ingredientes destinados à alimentação animal. In: SIMPÓSIO SOBRE INGREDIENTES NA ALIMENTAÇÃO ANimAL, 2001, Campinas. Anais... Campinas: Colégio Brasileiro de Nutrição Animal, 2001. p.235-272.

NUTRIENT REQUIREMENTS COUNCIL - NRC. Nutrient requirements of poultry. 9.ed. Washington, D.C., 1994. 155p.

OLIVEIRA, M.C.; MARTINS, F.F.; ALMEIDA, C.V. et al. Efeito da inclusão de bagaço de girassol na ração sobre o desempenho e rendimento de carcaça de frangos de corte. Revista Portuguesa de Zootecnia, v.10, n.2, p.107-116, 2003.

PINHEIRO, J.W.; FONSECA, N.A.N.; SILVA, C. A. et al. Farelo de girassol na alimentação de frangos de corte em diferentes fases de desenvolvimento. Revista Brasileira de Zootecnia, v.31, n.3, p.1418-1425, 2002 (supl.).

RAD, F.H.; KESHAVARZ, K. Evaluation of the nutritional value of sunflower meal and the possibility of substitution of sunflower meal for soybean meal in poultry diets. Poultry Science, v.55, n.5, p.1757-1764, 1976.

ROSTAGNO, H.S.; ALBINO, L.F.T.; DONZELE, J.L. et al. Tabelas brasileiras para aves e suínos: composição de alimentos e exigências nutricionais. 2.ed. Viçosa, MG: Editora UFV, 2005. $186 \mathrm{p}$.

SENKOYLU, N.; DALE, N. Sunflower meal in poultry diets. World Poultry Science Journal, v.55, n.6, p.153-174, 1999.

UNIVERSIDADE FEDERAL DE VIÇOSA - UFV. Sistema de análises estatísticas e genéticas - SAEG. Versão 8.0. Viçosa, MG, 2000. 142p.

VALDIVIE, M.; SARDINAS, O.; GARCIA, J.A. The utilization of $20 \%$ sunflower seed meal in broiler diets. Cuban Journal of Agricultural Science, v.16, n.2, p.167-171, 1982.

WALDROUP, P.W.; HILLARD, C.M.; MITCHELL, R.J. Sunflower meal as a protein supplement for broiler diets. Feedstuffs, v.42, n.43, p.41, 1970.

ZATARI, I.M.; SELL, J.L. Effects of pelleting diets containing sunflower meal on the performance of broiler chickens. Animal Feed Science and Technology, v.30, p.121-129, 1990. 